Original

Article

\title{
Endocrine cancer in Iran: Based on cancer registry system
}

\author{
Haghpanah V, Soliemanpour B, Heshmat R, Mosavi-Jarrahi AR*, Tavangar SM**, \\ Malekzadeh $\mathbf{R}^{\star \star \star}$, Larijani B \\ Endocrinology and Metabolism Research Center, Tehran University of Medical Sciences, Tehran, \\ ${ }^{*}$ The Cancer Institute Research Center, Tehran University of Medical Sciences, Tehran, \\ ${ }^{* \star}$ Department of Pathology, Shariati Hospital, Tehran University of Medical Sciences, Tehran, \\ ${ }^{* * *}$ Digestive Disease Research Center, Tehran University of Medical Sciences, Tehran, Iran
}

Correspondence to: Bagher Larijani, E-mail: emrc@sina.tums.ac.ir

\section{Abstract}

BACKGROUND: A population-based registry of endocrine cancer cases in four Iranian provinces, was performed for the years 1996-2000. MATERIALS AND METHODS: Patients in each province were grouped according to age, gender and tumor specifics (site, morphology, behavior) and the data was coded according to the international classification of diseases for oncology. STATISTICAL ANALYSIS USED: Person-years of population at risk were calculated and the results were presented as incidence rates by sex, age, age specific rates and age standard rate (ASR) per 100,000 person-years, using direct method of standardization to the world population. RESULTS: A total of 319 cases of primary endocrine cancer were found and registered, including 313 cases of thyroid carcinoma and 6 cases of adrenal cancer. The thyroid carcinoma group cases consisted of papillary (82.7\%), follicular (8.6\%), medullary $(7.0 \%)$ and anaplastic (1.6\%) carcinomas. The ASR for thyroid carcinoma was $1.289(0.627$ for men, 1.59 for women), with the highest incidence rate in Kerman (ASR 1.643) and the lowest incidence rate in Golestan (ASR 0.735). For the 6 cases of adrenal cancer, 4 were neuroblastoma and 2 were pheochromocytoma. CONCLUSIONS: Iran was considered as an endemic, iodine-deficient area, until fairly recently. lodinization of salt has been started about 12 years ago, in the nation. Considering the effect of improvement in the iodine intake in previously deficient communities, which is associated with an increase in the incidence of papillary carcinoma compared to other histologic types, the frequency and distribution of histologic types of thyroid carcinoma was closer to what can be seen in iodine-rich areas.

Key words: Neoplasm, endocrine, registry, Iran.

Cancer is a growing health problem in Iran and according to recent statistics, represents the third most common known cause of death after cardiovascular disease and accidents. ${ }^{[1]}$ Although endocrine cancers are relatively uncommon, they represent an important group of potentially treatable cancers. Thyroid carcinoma is the most common form of endocrine cancer, accounting for $\sim 1 \%$ of all new malignant diseases $(\sim 0.5 \%$ of cancers in men and $\sim 1.5 \%$ of cancers in women). ${ }^{[2,3]}$ Papillary carcinoma is the most common histological type of thyroid cancer in iodine rich areas and has the best prognosis compared to other histological types of thyroid cancer. ${ }^{[2,4]}$ Some authors have suggested that the mortality rate in patients with papillary carcinoma, may be the same as in the general population. ${ }^{[5]}$ Studies have also reported an increasing incidence of thyroid carcinoma and particularly papillary histology. ${ }^{[6-8]}$ In a survey by the cancer institute of Iran, thyroid carcinoma constituted $\sim 76.1 \%$ of all cases of endocrine cancer, ${ }^{[9]}$ but a more recent study on thyroid carcinoma survival in Iran, have shown that $\sim 28.6 \%$ of the cases of the thyroid carcinoma were diagnosed, following 
metastasis. ${ }^{[10]}$

Cancer registration is in its infancy in Iran and in recent years there has been an increasing demand for reliable cancer data, by national researchers and health officials. ${ }^{[1]}$ In order to encourage programs on prevention and early diagnosis of cancer, the endocrine and metabolism research center (EMRC) has gathered and registered all known cases of endocrine cancer in four Iranian provinces (Kerman, Mazandaran, Gilan and Golestan), between 1996 and 2000. The EMRC plans to extend this project to cover other regions in Iran.

Kerman is the $3^{\text {rd }}$ largest province in Iran, situated in the south east of the country, with a population of $\sim 2004328$ and area of $\sim 180000 \mathrm{sq} \mathrm{km}$. It consists mostly of steppe and sandy desert. ${ }^{[12]}$ The other three provinces lie along the coast of the Caspian sea in the north of Iran and are bordered by the Alborz Mountains to the south. Golestan province covers area of $\sim 20311 \mathrm{sq} \mathrm{km}$, Mazandaran $\sim 46656 \mathrm{sq} \mathrm{km}$ and Guilan $\sim 14700 \mathrm{sq} \mathrm{km}$. The population of Golestan, Mazandaran and Guilan are $\sim 1522468, \sim 1740772$ and $\sim 2241896$, respectively. ${ }^{[12]}$ All three provinces have a moderate and humid climate known as "the moderate Caspian climate" [Figure 1].

The city of Ramsar is situated in the west of Manzandaran (Mazandaran province is a large province that include several cities) and has a high level of background radiation. People in some areas of Ramsar receive an annual radiation dose of $\sim 260 \mathrm{mSv}^{-1}$, much higher than the $20 \mathrm{mSv} \mathrm{y}^{-1}$, that is permitted for radiation workers in Iran. Despite this high radiation exposure however, levels of cytogenetic changes and chromosome aberrations in the population of Ramsar

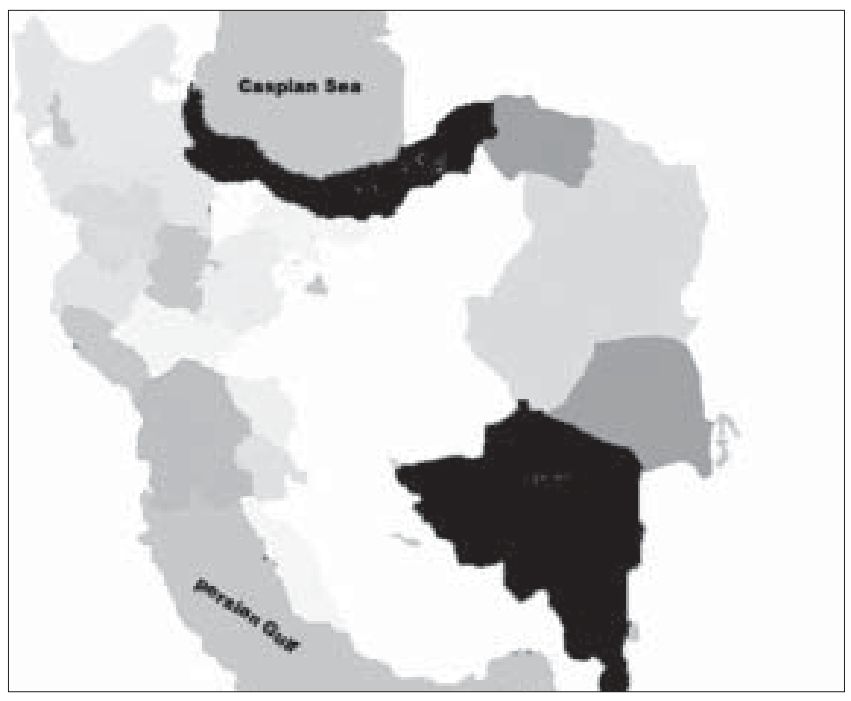

Figure 1: Map of Iran and four provinces (Black areas). are not significantly higher than in other cities. ${ }^{[13]}$

\section{Materials and Methods}

This study is a retrospective analysis of the medical records of patients, with a confirmed diagnosis of endocrine cancer. According to the WHO's international classification of diseases for oncology (ICD-O 10), endocrine neoplasms are classified as either: thyroid, adrenal, or other endocrine glands and related structures, including: parathyroid, pituitary, pineal, craniopharyngeal duct, carotid body, aortic body and paraganglia. ${ }^{[14]}$

Over a period of 6 months, the survey team visited hospitals, pathology laboratories, radiology clinics, public/private outpatient clinics and death registrars in each of the four regions, to check for records of endocrine cancer dated between 1996 and 2000 . Whenever possible, copies were taken of the documents where a diagnosis of endocrine cancer was made. These were sent to the medical registry office in the capital of each province and from there to the EMRC. Most private radiology centers recorded the identifying data of subjects and only occasionally kept the radiologic or sonographic reports, while the public centers, usually located in the hospitals, kept radiology reports for the majority of patients.

Information on patient mortality was evaluated by both the certificate of death and the annual health census. In all four provinces, physicians issue death certificates in duplicate, one for themselves (which is later sent to the deputy of drugs and treatment in the capital of each province) and one for the graveyard authorities. Death certificates from urban areas were obtained from the office of medical documents in the deputy of drug and treatment. The deputy of health, responsible for the rural areas of the four provinces, conducts an annual health census using behvarzes (auxiliary health-care workers in health houses, who are responsible for public health care and the health census of each village). This occurs at the beginning of each year and involves the behvarzes going from house to house, collating data on the number of new births and deaths (as well as the cause of death). The results of the census are compiled by the deputy of health, resulting in the annual death statistics. The survey team were fortunate to enjoy the close collaboration of all of the health authorities and physicians in these four provinces, in providing the necessary data and documents for this study.

Data were summarized in a data sheet, coded according to the ICD-O ${ }^{[14]}$ and organized alphabetically. Duplicate 
cases, where an individual had attended multiple centers/hospitals, resulting in entries with the same name, gender, age and place of residence, were eliminated by manual and computerized linkage. Each alphabetical group was assessed manually by two individuals, on two different occasions. Data were computerized and analysed statistically using SPSS v11.5 (Chicago, USA) and Microsoft EXCEL (Redmond, USA) and the person-years of the population at risk, was calculated. Data were presented as incidence rates of: cases by site (ICD-O), gender, age, age, specific rates (ASR) and ASRs per 100,000 person years (using the direct method of standardization to the world population. ${ }^{[15]}$

\section{Results}

For the period 1996-2000, 319 cases of endocrine cancer were found and registered in the four provinces. These included 79 men $(24.8 \%)$ and 240 women $(75.2 \%)$, with ages ranging from 3-80 for thyroid carcinoma and 9-26 for adrenal malignancies. The mean age of the patients at the time of diagnosis was 43.38 years $(S D=16.22), 43.99$ years for men $(S D=17.91)$ and 43.18 years for women $(S D=15.66)(\mathrm{df}=317$, $P=0.70)$, respectively. Thyroid carcinoma accounted for 313 cases $(98.1 \%)$ and adrenal cancer- 6 cases (1.9\%). No malignant tumors of the other endocrine organs were reported.

Of the 313 cases of thyroid carcinoma, 237 (75.7\%) were women and $76(24.3 \%)$ were men. The mean age at diagnosis for thyroid carcinoma was 43.90 years $(\mathrm{SD}=15.90), 45.21$ years for $\operatorname{men}(\mathrm{SD}=17.13)$ and 43.49 years for women $(\mathrm{SD}=15.5 \mathrm{l})(\mathrm{df}=311$, $P=0.41)$. For the various histological subtypes of thyroid carcinoma, the mean age at diagnosis was as follows: Papillary carcinoma 42.90 years $(S D=15.07)$, 44.56 years $(S D=15.48)$ for men and 42.37 years $(\mathrm{SD}=14.94)$ for women; Follicular carcinoma 45.37 years $(S D=18.19), 33.00$ years $(S D=18.01)$ for men and 48.18 years $(S D=17.41)$ for women; medullary carcinoma 48.50 years $(S D=18.61), 55.57$ years $(\mathrm{SD}=23.93)$ for men and 45.20 years $(S D=15.41)$ for women; anaplastic carcinoma 67.60 years $(S D=14.36)$, 75.00 years $(S D=0.00)$ for men and 65.75 years $(\mathrm{SD}=15.88)$ for women.

The mean age at diagnosis for adrenal cancer was 16.17 years $(S D=7.05), 13.00$ years $(S D=3.46)$ for men and 19.33 years $(\mathrm{SD}=9.07)$ for women $(\mathrm{df}=4, P=0.32)$.

The ASR for thyroid carcinoma was $1.289(0.627$ for men, 1.59 for women), with the highest incidence rate in Kerman (ASR 1.643) and the lowest incidence rate in Golestan (ASR 0.735). For the 6 cases of adrenal cancer, 4 were neuroblastoma and 2 were pheochromocytoma. The ASR for adrenal carcinoma was 0.017 (0.016 for male, 0.017 for female), with the highest incidence rate in Kerman (ASR 0.042) and the lowest incidence rate in Golestan and Gilan (ASR $0.000)$.

Table 1 shows the age-specific incidence rates, annual crude rates and standardized incidence rates (ASR world) of thyroid carcinoma respectively, for total, male and female patients. Table 2 shows histologic types of thyroid and adrenal cancers, divided by gender. [Figure 2] shows age and sex-specific incidence rates for thyroid carcinoma.

\section{Discussion}

Based on Globocan 2002, the estimated world age adjust population incidence for thyroid cancer in the world, ranges from highest to lowest, in the USA Hawaii: Filipino (Male: 5.8 D 100000), USA Hawaii: Filipino (Female: 20.6 D 100000) and China Qidong County (Male: 0.2 D 100000), China Qidong County (Female: $0.6 \mathrm{D}$ 100000). The same figure for thyroid in Asia is: highest in Israel (Male: 4 D 100000, Female 11.4 D 100000) and lowest in China (Male: 0.2 D 100000, Female: 0.6 D 100000); for adrenal gland: highest in Japan and Israel (Male: 1.0 D 100000) Korea (Female: 1.5 D 100000) and the lowest is 0.0 in some country for both sex (Thailand); for other endocrine: highest in China (Male: 1.1 D 100000, Female: $1.4 \mathrm{D}$ 100000) and the lowest is 0.0 in some country (India).

The female to male ratio for endocrine cancer in our study was 3 to 1 and the ratio for thyroid carcinoma 3.1 to 1 , both of which show a female disease predominance, similar to other studies. ${ }^{[16]}$ The standardized incidence rate for thyroid carcinoma (ASR) in all four provinces was 1.29 (1.96 for women and 0.63 for men). These rates are lower than those reported by Globocan for Iran in 2000, ${ }^{[17]}$ which gave ASRw of 2.09 for men and 5.06 for women. The ineffective registration of thyroid carcinoma could be one of the important reason for the lower incidences in our study.

In fact, the Globocan 2000 for Iran, is an estimated figure based on data from its neighboring countries. So, it would be misleading to compare our data and Globocan 2000. Nevertheless, Globocan 2002, which is based on domestic data, closely correlates our data.

Kerman with ASRw of 1.64 and Golestan with ASRw 
Table 1: Age specific incident rates, average annual crude rates per 100000 per year and ASR of thyroid carcinoma in four provinces

\begin{tabular}{|c|c|c|c|c|c|c|c|c|c|}
\hline \multirow[t]{2}{*}{ Site } & \multirow[t]{2}{*}{ Province } & \multicolumn{7}{|c|}{ Age ranges } & \multirow[t]{2}{*}{ Crude rate (ASR world) } \\
\hline & & $0-14$ & $15-24$ & $25-34$ & $35-44$ & $45-54$ & $55-64$ & $\geq 65$ & \\
\hline \multirow[t]{5}{*}{ Thyroidmales } & Kerman & 0 & 0.117 & 0.385 & 1.462 & 0.966 & 1.112 & 3.233 & $0.467(0.671)$ \\
\hline & Mazandaran & 0.078 & 0.443 & 1.154 & 1.903 & 0.903 & 0.527 & 1.618 & $0.666(0.744)$ \\
\hline & Guilan & 0 & 0 & 1.032 & 0.771 & 0.637 & 2.161 & 1.572 & $0.516(0.590)$ \\
\hline & Golestan & 0 & 0.262 & 0.212 & 0.888 & 1.984 & 0 & 0.750 & $0.355(0.452)$ \\
\hline & Total & 0.018 & 0.192 & 0.731 & 1.223 & 1.059 & 1.174 & 1.845 & $0.504(0.627)$ \\
\hline \multirow[t]{5}{*}{ Thyroidfemales } & Kerman & 0.180 & 0.609 & 2.459 & 5.022 & 6.188 & 3.138 & 8.876 & $1.851(2.659)$ \\
\hline & Mazandaran & 0.240 & 0.542 & 2.807 & 5.861 & 3.707 & 3.299 & 2.951 & $1.851(2.141)$ \\
\hline & Guilan & 0 & 0.532 & 2.742 & 4.194 & 2.206 & 5.426 & 3.542 & $1.687(1.902)$ \\
\hline & Golestan & 0.101 & 0 & 0.630 & 2.686 & 1.930 & 1.682 & 3.517 & $0.769(1.035)$ \\
\hline & Total & 0.129 & 0.431 & 2.240 & 4.484 & 3.376 & 3.760 & 4.604 & 1.585 (1.959) \\
\hline \multirow[t]{5}{*}{ Thyroidtotal } & Kerman & 0.089 & 0.359 & 1.431 & 3.215 & 3.596 & 2.064 & 5.826 & $1.148(1.643)$ \\
\hline & Mazandaran & 0.158 & 0.494 & 1.991 & 3.946 & 2.369 & 1.883 & 2.255 & $1.264(1.454)$ \\
\hline & Guilan & 0 & 0.281 & 1.897 & 2.492 & 1.426 & 3.734 & 2.556 & $1.104(1.247)$ \\
\hline & Golestan & 0.049 & 0.132 & 0.422 & 1.783 & 1.957 & 0.840 & 2.024 & $0.558(0.735)$ \\
\hline & Total & 0.072 & 0.313 & 1.493 & 2.861 & 2.238 & 2.423 & 3.164 & 1.042 (1.289) \\
\hline
\end{tabular}

Table 2: Histologic types of thyroid and adrenal cancer divided by gender.

\begin{tabular}{|c|c|c|c|c|}
\hline \multirow[t]{2}{*}{ Site } & \multirow[t]{2}{*}{ Morphology } & \multicolumn{2}{|c|}{ Gender } & \multirow[t]{2}{*}{ Total (\%) } \\
\hline & & $\begin{array}{l}\text { Male } \\
(\%)^{\star}\end{array}$ & $\begin{array}{c}\text { Female } \\
(\%)^{\star}\end{array}$ & \\
\hline \multirow[t]{5}{*}{ Thyroid } & Papillary carcinoma & $63(24.3)$ & $196(75.7)$ & 259 (82.7) \\
\hline & Follicular carcinoma & $5(18.5)$ & $22(81.5)$ & $27(8.6)$ \\
\hline & Medullary carcinoma & 7 (31.8) & $15(68.2)$ & $22(7.0)$ \\
\hline & Anaplastic carcinoma & $1(20.0)$ & $4(80.0)$ & $5(1.6)$ \\
\hline & Total & $76(24.3)$ & 237 (75.7) & $313(100)$ \\
\hline \multirow[t]{3}{*}{ Adrenal } & Neuroblastoma & $2(50.0)$ & $2(50.0)$ & $4(66.7)$ \\
\hline & Pheochromocytoma & $1(50.0)$ & $1(50.0)$ & 2 (33.3) \\
\hline & Total & $3(50.0)$ & $3(50.0)$ & $6(100)$ \\
\hline
\end{tabular}

*Percentages were calculated between gender groups for each histologic type

of 0.74 , had respectively the highest and the lowest incidence of thyroid cancer rates from the four provinces. The mean age of the cases of thyroid carcinoma was 43.9 years (45.21 years for men and 43.49 for women), which is consistent with other studies that show the average age of women at

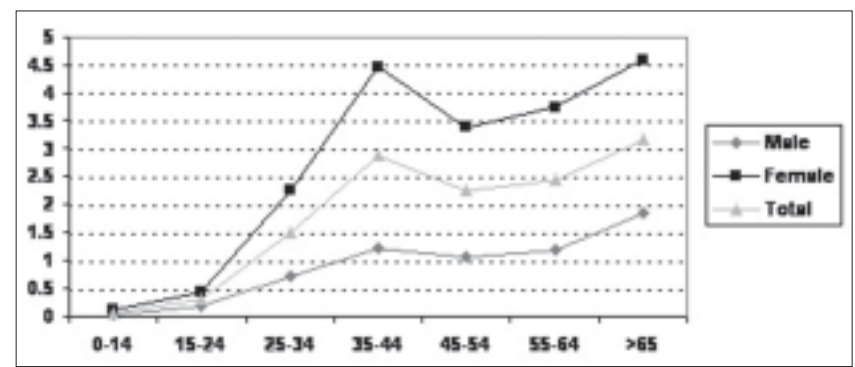

Figure 2: Age and sex specific incidence rates of thyroid cancer.

diagnosis of thyroid cancer to be lower. ${ }^{[10,18]}$ When comparing the data from this study with a similar study performed in Tehran in 1998-99, the patients were found to be younger and the age difference between male and female cases was lower in this study. ${ }^{[18]}$

Cancers of the thyroid are relatively uncommon in different areas of the world. The epidemiologic features are well established and studied in most of the developed countries, as well as in some developing countries. ${ }^{[19]}$

Epidemiologic studies report a progressive increase in the incidence of thyroid carcinoma ${ }^{[2]}$ and such studies have shown higher rates of thyroid cancer in populations with a higher iodine intake. ${ }^{[20]}$ Improved 
iodine intake in previously deficient communities has also been associated with an increased incidence rate of papillary thyroid carcinoma. ${ }^{[8]}$ This so-called papillarization is characterized by an increase in the ratio of papillary to follicular carcinoma. ${ }^{[21]}$ According to Bacher-Stier et al, the normalization of the iodine supply in a region with an endemic goiter problem, results in a change in the epidemiological profile of thyroid carcinoma. Despite the rise in incidence, however, the prognosis for thyroid cancer has significantly improved due to a shift towards identifying differentiated forms of thyroid carcinoma, that can be diagnosed at an earlier stage. ${ }^{[8]}$

Iran was previously an iodine deficient area, but $\sim 12$ years ago, the government instituted a nation wide iodine supplementation program. ${ }^{[22]}$ The result of our study is in accordance with other recent studies on the incidence of thyroid carcinoma in Iran, showing a high rate of papillary carcinoma and a low rate of follicular carcinoma. ${ }^{[18]}$ Previous studies have shown that the most prevalent histology in an endemic goiter region is follicular, ${ }^{[5,23]}$ but if we consider that for $\sim 12$ years salt has been iodinized in this region, resulting in a decrease in the prevalence of thyroid goiter, ${ }^{[24]}$ the increase in the incidence of papillary carcinoma can be explained. In addition, previous studies in Iran have shown that even before the salt iodinization process was initiated, papillary carcinoma was the most prevalent histology in Iran. ${ }^{[18]}$

Anaplastic carcinoma of thyroid, the most aggressive solid tumor known, ${ }^{[25]}$ constituted $\sim 1.6 \%$ of all thyroid carcinoma cases in this study. In contrast to previous studies, the incidence of anaplastic carcinoma was higher in females than in males. ${ }^{\left[{ }^{[8,18}\right]}$ Of the five cases of anaplastic carcinoma registered, four were female. This could be due to low registration coverage, but it is data that needs to be reinvestigated in the future. Previous data has shown that following the introduction of iodine supplementation in iodine deficient areas, the proportion of papillary thyroid carcinoma has increased, while cases of anaplastic thyroid carcinoma have decreased. ${ }^{[8]}$ This decline in the relative proportion of anaplastic carcinoma, may in part be explained by the clinicopathological findings or attributed to histological reclassification. ${ }^{[26]}$ Patients with anaplastic thyroid carcinoma in this study were older than the patients in other groups, which is consistent with previous studies. ${ }^{[8]}$

While the study indicates low frequency of endocrine cancers in Iran, it should not be neglected that it was limited to only four provinces of the country and it was limitation of data. This could restrict its value as a representation of all nations.

\section{References}

1. Naghavi M. Death reports from ten provinces in Iran $1^{\text {st }}$ ed. Ministry of Health: Tehran; 2000.

2. Deandrea M, Gallone G, Veglio M, Balsamo A, Grassi A, Sapelli S, et al. Thyroid cancer histotype changes as observed in a major general Hospital in a 21 year period. J Endocrinol Invest 1997;20:52-8.

3. Figge J. Epidemiology of thyroid cancer. In: Wartofsky L, editors. Thyroid cancer: A comprehensive guide to clinical management. Totowa: Humana press; 1999. p. 77-83.

4. Reynolds P, Elkin EP, Layefsky ME, Lee GM. Cancer in California school employees, 1988-1992. Am J Indian Med 1999;36:271-8.

5. Coard KC. The pathology of thyroid neoplasm at the University Hospital of West Indies. A 10 -year analysis. West Indian Med J 1997;46:80-2.

6. Verkooijen HM, Fioretta G, Pache JC, Franceschi S, Raymond L, Schubert $\mathrm{H}$, et al. Diagnostic changes as a reason for the increase in papillary thyroid cancer incidence in Geneva, Switzereland. Cancer Causes Control 2003; 14:13-7.

7. Colonna M, Grosclaude P, Remontet L, Schvartz C, Mace-Lesech $\mathrm{J}$, Velten $\mathrm{M}$, et al. Incidence of thyroid cancer in adults recorded by French cancer registries (1978-1997). Eur J Cancer 2002;38: 1762-8.

8. Bacher-Stier C, Riccabona G, Totsch M, Kemmler G, Oberaigner W, Moncayo R. Incidence and clinical characteristics of thyroid carcinoma after iodine prophylaxis in an endemic goiter country. Thyroid 1997;7:733-41.

9. Mohagheghi M, Moosavi JA, Shariat TS. Annual report of Tehran University of Medical Sciences, District Cancer Registry in 1997.

10. Larijani B, Aghakhani S, Khajeh-Dini H, Baradar-Jalili R. Clinicopathological features of thyroid cancer as observed in 5 referral Hospitals in Iran- A review of 1177 cases. Acta Oncol 2003;42:334-7.

11. Sadjadi A, Malekzadeh R, Derakhshan MH, Sepehr A, Nouraie M, Sotoudeh M, et al. Cancer occurrence in Ardabil, Results of a populated based cancer registry from Iran. Int J Cancer 2003; 107:113-8.

12. Statistical Center of Iran, Iran statistics year book, Tehran. Statistical center of Iran: 1999.

13. Ghiassi-Nejad M, Mortazavi SM, Cameron JR, Niroomand-Rad A, Karam PA. Very high background radiation areas of Ramsar, Iran. Preliminary biological studies. Health Phys 2002;82:87-93.

14. Fritz PA, Percy C, Jack A, Shanmugaratnuers K, Solin L, Parkin $\mathrm{DM}$, et al. International classification of diseases for oncology. $3^{\text {rd }}$ ed. WHO: Geneva; 2000.

15. Isabel dos Santos Silva. Cancer Epidemiology: Principles and methods, IARC: 1999.

16. Correa P, Chen VW. Endocrine gland cancer. Cancer 1995;75:33852.

17. Ferlay J, Bray B, Pisani P, Parkin DM. Globocan 2000. Cancer incidence, mortality and prevalence worldwide. IARC: Lyon; 2001.

18. Larijani B, Shirzad M, Mohagheghi MA, Haghpanah V, MosaviJarrahi AR, Tavangar SM, et al. Epidemiologic analysis of Tehran Cancer Institute Data System Registry:Focus on thyroid cancer. Asian Pac J Cancer Prev 2004;5:36-9.

19. Larijani B, Mohagheghi MA, Bastanhagh MH, Mosavi-Jarrahi AR, Haghpanah V, Tavangar SM, et al. Primary malignancies of thyroid in Tehran, Iran. Med Princ Pract 2005; 14:396-400.

20. Parkin DM, Muir CS, Whelan SL. Cancer incidence in five continents. IARC Sci Pub: Lyon; 1999.

21. Pettersson B, Coleman MP, Ron E, Adami HO. Iodine supplementation in Sweden and regional trends in thyroid cancer incidence by histopathologic type. Int J Cancer 1996;65:13-9. 
22. Kimiagar M, Azizi F, Navai L, Yassai M, Nafarabadi T. Survey of iodine deficiency in a rural area near Tehran: Association of food intake and endemic goiter. Eur J Clin Nutr 1990;44:17-22.

23. Frich L, Akslen LA, Glattre E. Increased risk of thyroid cancer among Norwegian women married to fishery workers: A retrospective cohort study. BJC 1997;76:385-9.

24. Azizi F, Navai L, Fattahi F. Goiter prevalence, urinary iodine excretion, thyroid function and anti-thyroid function and anti- thyroid antibodies after 12 years of salt iodization in Shahriar, Iran. Int J Vitam Nutr Res 2002;72:291-5.

25. Ain KB. Anaplastic thyroid carcinoma: Behavior, biology and therapeutic approaches Thyroid 1998;8:715-26.

26. Agrawal S, Rao RS, Parikh DM, Parikh HK, Borges AM, Sampat MB. Histologic trends in thyroid cancer 1969-1993: A clinico pathologic analysis of the relative proportion of anaplastic carcinoma of the thyroid. J Surg Oncol 1996;63:251-5. 